\title{
Experimental Research on Passive Residual Heat Removal System of Chinese Advanced PWR
}

\author{
Zhuo Wenbin, Huang Yanping, Xiao Zejun, Peng Chuanxin, and Lu Sansan \\ CNNC Key Laboratory on Nuclear Reactor Thermal Hydraulics Technology, Nuclear Power Institute of China, Chengdu 610041, China \\ Correspondence should be addressed to Zhuo Wenbin; npic011371@163.com
}

Received 6 December 2013; Accepted 24 February 2014; Published 5 June 2014

Academic Editor: Shengqiang Li

Copyright ( 2014 Zhuo Wenbin et al. This is an open access article distributed under the Creative Commons Attribution License, which permits unrestricted use, distribution, and reproduction in any medium, provided the original work is properly cited.

\begin{abstract}
Passive residual heat removal system (PRHRS) for the secondary loop is one of the important features for Chinese advance pressurized water reactor (CAPWR). To prove the safety characteristics of CAPWR, serials of experiments have been done on special designed PRHRS test facility in the former stage. The test facility was built up following the scaling laws to preserve the similarity to CAPWR. A total of more than 300 tests have been performed on the test facility, including $90 \%$ steady state cases and $10 \%$ transient cases. A semiempirical model was generated for passive heat removal functions based on the experimental results of steady state cases. The dynamic capability characteristics and reliability of passive safety system for CAPWR were evidently proved by transient cases. A new simulation code, MISAP2.0, has been developed and calibrated by experimental results. It will be applied in future design evaluation and optimization works.
\end{abstract}

\section{Introduction}

The passive safety feature is one important essential requirement for both integral type reactors and large scale multiloop type reactors. The steam generators (SGs) have been considered as passive safety cooling devices to provide primary loop decay heat removal capacity. There is no additional power supply needed for SGs cooling features. It is specially fit for nonloss of coolant accident applications. The steam released from SGs will be condensed in an accessory heat exchanger, which is located in a tank and submerged in low temperature coolant. To enhance the passive safety function and provide a redundant heat removal path, the secondary side passive cooling system will be necessary for advanced reactors.

In order to improve the security and reliability of reactor, some evolutionary and innovative reactors, such as AP600/1000, WWER640/407, APR+, SBWR, and SMART, employ passive residual heat removal systems [1]. But most of these systems are primary passive cooling systems, except for WWER640/407 and APR+. The passive heat removal system for the WWER640/407 reactor is located at the secondary side of SG. In case of non-LOCAs the decay heat is removed by coolant natural circulation to steam generator boiler water. The steam generated comes into the passive heat removal system where steam is condensed on the internal surface of the tubes that are cooled on the outside surface by the water stored in the demineralized water tank outside the containment. The water inventory in this tank is sufficient for the long-term heat removal (at least 24 hours) and can be replenished if necessary from an external source [2].

The APR+ is a Generation III+ nuclear power plant being developed in Korea. The passive auxiliary feedwater system (SG secondary side passive residual heat removal system) is one of the advanced safety features being adopted in the APR+. It cools down the secondary side of the steam generator and eventually removes the decay heat from the reactor core by adopting a natural circulation mechanism, that is, condensing steam in the nearly horizontal passive condensation heat exchanger tubes submerged inside the passive condensation cooling tank [3].

The SG secondary side passive residual heat removal system (PRHRS), which removes the residual heat when station blackout occurs, is considered in Chinese advanced PWR. The passive residual heat removal system eliminates a great deal of water in the condensation tank, which is cooled by air natural circulation in the chimney. Only a small quantity of water in the emergency feedwater tank is needed for absorption of residual heat at the initial period of accident. 


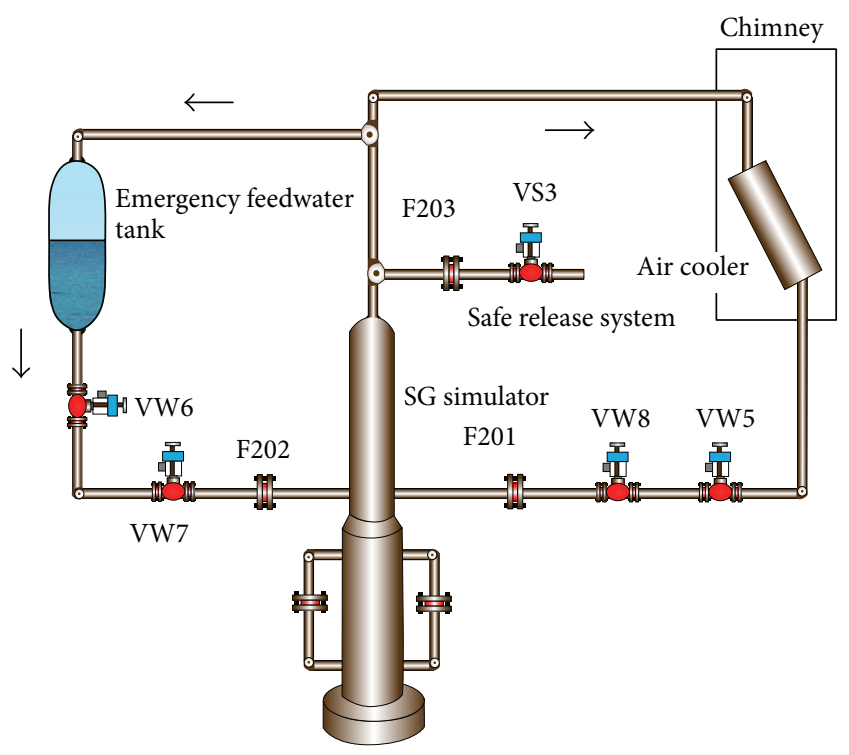

FIGURE 1: Schematic diagram of PRHRS test facility.

In order to assess the ability of PRHRS, experimental research had been done at advanced PWR PRHRS test facility in Nuclear Power Institute of China; in the meantime, the computer code MISAP2.0 has been developed and verified.

\section{Test Facility}

The test facility has been built according to two-phase natural circulation scaling methodology laws. The geometrical similarity, friction number, density ratio, Froude number, phase change number, and drift-flux number are the important similarity groups. And it is composed of steam-water circulation loop, emergency feedwater loop, air natural circulation loop, and safe release system. The main components include steam generator, air cooler, emergency feedwater tank (EFWT), and chimney. It has a geometrical scaling ratio of $1 / 390$ in volume, and the total height from the top of the height-adjustable chimney to the bottom of SG is about $23 \mathrm{~m}$. The maximal pressure of facility is $8.6 \mathrm{MPa}$, and the core decay heat is simulated by electric heaters with a capacity of $400 \mathrm{~kW}$ (DC). Figure 1 shows its schematic diagram.

The work principle of test facility is as follows. When station blackout or other accidents occur, the isolation valves located at the outlet pipe of emergency tank are opened by a low-low water signal for the SG, so that the emergency water tank provides water to the secondary side of SG driven by gravity and maintains the water level. The water in the SG absorbs the residual heat when the water evaporates. The steam rises and passes through the air cooler where the steam is condensed into water; simultaneously, the heat is transferred into the air through the air natural circulation composed of chimney and atmosphere. Then, the condensed water returns to the SG loop driven by gravity; thereby, a continuous natural circulation flow is established.

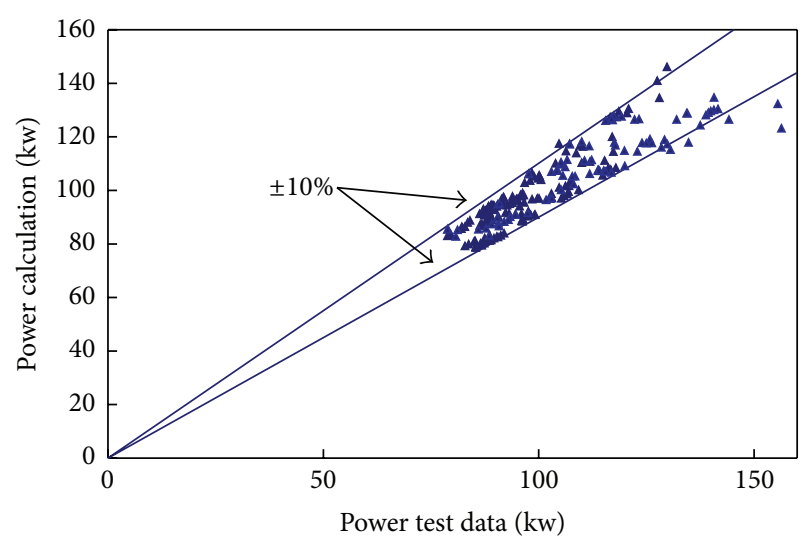

Figure 2: Power comparison between test and calculation.

\section{Test Matrix and Startup Modes}

A total of 280 sets of experimental data at steady state have been obtained and the main influence factors on heat removal capability were identified. The main operation parameters are the height of chimney, the hydraulic resistance, and the initial pressure.

More than 30 transient tests had been performed while the residual heat drops from $8 \%$ full power to $2 \%$ full power (Figure 2). In addition the influence factors on flow instability were identified.

\section{Test Results and Analysis}

4.1. Steady Test. The natural circulation is influenced by many parameters, such as the height of chimney, the hydraulic resistance, and the initial pressure. Several tests are implemented to investigate the effect of these parameters on the passive residual heat removal system. In addition a semiempirical model was generated for predicting the natural circulation behavior of Chinese advance pressurized water reactor.

The equation of momentum for passive residual heat removal loop is

$$
\left(\rho_{w} L_{w}-\rho_{s} L_{s}-\rho_{s g} L_{s g}\right) g=\frac{k_{w} w^{2}}{2 \rho_{w} A_{W}^{2}}+\frac{k_{s} w^{2}}{2 \rho_{s} A_{s}^{2}},
$$

where the subscripts $w, s$, and $s g$ are water in the down pipe, steam in the rise pipe, and SG respectively.

Equation of momentum for air loop is

$$
\left(\rho_{y}-\rho_{y i}\right) g L_{y}=\frac{k_{y} w_{a}^{2}}{2 \rho_{y} A_{y}^{2}}
$$

where the subscripts $y$ and $y i$ are outlet and inlet of chimney, respectively.

The air cooler heat transfer equation is

$$
Q=K F \Delta T_{m}
$$

In steam side of the cooler,

$$
Q=W\left(H_{s}-H_{w}\right)
$$


TABLE 1: Effect of the height of chimney.

\begin{tabular}{|c|c|c|c|c|c|c|c|}
\hline \multirow[b]{2}{*}{ Number } & \multirow[b]{2}{*}{$\begin{array}{l}\text { Height of chimney } \\
\text { (m) }\end{array}$} & \multicolumn{3}{|c|}{ Test } & \multicolumn{3}{|c|}{ Calculation } \\
\hline & & $\begin{array}{c}\text { Natural circulation } \\
\text { flow rate }(\mathrm{kg} / \mathrm{h})\end{array}$ & $\begin{array}{c}\text { Temp. of } \\
\text { condensate }\left({ }^{\circ} \mathrm{C}\right)\end{array}$ & $\begin{array}{c}\text { Power } \\
(\mathrm{kW})\end{array}$ & $\begin{array}{l}\text { Natural circulation flow } \\
\text { rate }(\mathrm{kg} / \mathrm{h})\end{array}$ & $\begin{array}{c}\text { Temp. of } \\
\text { condensate }\left({ }^{\circ} \mathrm{C}\right)\end{array}$ & $\begin{array}{c}\text { Power } \\
(\mathrm{kW})\end{array}$ \\
\hline 1 & 9.7 & 204.4 & 280.2 & 86.7 & 210.3 & 277.09 & 90.8 \\
\hline 2 & 14.1 & 226.4 & 279.6 & 96.5 & 236.7 & 278.66 & 101.7 \\
\hline 3 & 14.8 & 230.9 & 280.9 & 97.2 & 235.6 & 273.87 & 102.8 \\
\hline 4 & 21.1 & 238.5 & 263.1 & 107.4 & 249.5 & 256.16 & 115.1 \\
\hline 5 & 27.1 & 249.0 & 243.7 & 119.1 & 259.3 & 237.96 & 125.8 \\
\hline
\end{tabular}

The height between air cooler and SG is $14.5 \mathrm{~m}$, the hydraulic resistance is 105 , the water in SG is $5.1 \mathrm{~m}$, the pressure is $6.4 \mathrm{MPa}$, and the temperature at the inlet is $20^{\circ} \mathrm{C}$.

TABLE 2: Effect of the hydraulic resistance.

\begin{tabular}{|c|c|c|c|c|c|}
\hline \multirow{2}{*}{\multicolumn{2}{|c|}{ Number Hydraulic resistance (m) }} & \multicolumn{2}{|l|}{ Test } & \multicolumn{2}{|l|}{ Calculation } \\
\hline & & Natural circulation flow rate $(\mathrm{kg} / \mathrm{h})$ & Power $(\mathrm{kW})$ & Natural circulation flow rate $(\mathrm{kg} / \mathrm{h})$ & Power $(\mathrm{kW})$ \\
\hline 1 & 86 & 215.6 & 89.4 & 227 & 92.7 \\
\hline 2 & 122 & 211.0 & 88.5 & 221 & 91.9 \\
\hline 3 & 153 & 210.1 & 88.2 & 220 & 92.7 \\
\hline 4 & 157 & 209.4 & 87.9 & 219 & 92.5 \\
\hline 5 & 171 & 206.7 & 87.6 & 217 & 91.7 \\
\hline
\end{tabular}

The height between air cooler and SG is $14.5 \mathrm{~m}$, the height of chimney is 10.5 , the water in SG is $5.1 \mathrm{~m}$, the pressure is $6.4 \mathrm{MPa}$, and the temperature at the inlet is $20^{\circ} \mathrm{C}$.

In air side of the cooler,

$$
Q=W_{a}\left(H_{y}-H_{y i}\right)
$$

where $K$ is heat transfer coefficient, $F$ is heat transfer area, $\Delta T_{m}$ is mean temperature difference, and $W_{a}$ is the air flow rate.

Coupling with (1)-(5), a semiempirical correlation has been built up for total PRHR system heat transfer estimation based on the test results. In this case, when system pressure, water level in SG, friction coefficient, and the height between SG and air cooler are given, the ability of heat removal can be calculated. Consider

$$
Q=268 \times \frac{(0.98-L \text { th } / 30)^{-0.05} \times(0.8 \operatorname{Ln} H+1.2)}{(7.06-1.23 \operatorname{Ln} P) e^{(0.05 / 100) K} \times t_{\text {in }}^{0.2}}
$$

Sensitivity studies on different structure parameters have been made. The results will be described in detail as follows.

4.1.1. Effect of the Height of Chimney. The effect of the height of chimney in the passive residual heat removal system has been identified at the initial height of chimney of $9.7 \mathrm{~m}$ and $27.1 \mathrm{~m}$. In this group of sensitive studies, the hydraulic resistance hardly keeps the same value under different condition, which is maintained at less than $10 \%$. And the temperature of air at the inlet of chimney and pressure are unchanged values with only the height being allowed to change to find the effect.

Table 1 shows the experimental data and calculation of the natural circulation flow rate, power, and temperature of condensate, respectively. As the height of chimney increases, the natural circulation flow rate of air loop and power of air cooler rise. Then, the temperature of condensate decreases.
When the height between air cooler and SG and hydraulic resistance is constant, the reduced density of condensate causes the increase of natural circulation flow rate. In addition the calculation shows good agreement with experimental data.

4.1.2. Effect of the Hydraulic Resistance. The effects of the hydraulic resistance (frictional resistance and local resistance) in the passive residual heat removal system are performed in this study (Table 2). Other parameters are kept at a constant value. The hydraulic resistance is varied from 86 to 171 . We can see that the resistance increases more than $100 \%$, but the natural circulation flow rate and power decrease rarely. Therefore, the hydraulic resistance has little influence on the passive residual heat removal system.

4.1.3. Effect of the Initial Pressure on the Passive Residual Heat Removal System. The initial pressure in the passive residual heat removal system changes from 3.53 MPa to 7.30 MPa, and other parameters are fixed except for the hydraulic resistance with a 10 percent deviation. As the pressure ascends, the increase of power and natural circulation flow rate is $22.3 \%$ and $25 \%$, respectively (Table 3 ).

4.2. Transient Test. When the station blackout accident happens in the Chinese advance pressurized water reactor, it adopts the passive residual heat removal system to mitigate consequences of accidents. The passive residual heat removal system startup modes include warm and cold patterns when the emergency feedwater is on or off, respectively. If there is a tiny flow rate to keep a little natural circulation in both steam-water circulation loop and air natural circulation loop 
TABLE 3: Effect of the initial pressure.

\begin{tabular}{|c|c|c|c|c|c|}
\hline \multirow{2}{*}{ Number } & \multirow{2}{*}{ Pressure $(\mathrm{MPa})$} & \multicolumn{2}{|l|}{ Test } & \multicolumn{2}{|l|}{ Calculation } \\
\hline & & Natural circulation flow rate $(\mathrm{kg} / \mathrm{h})$ & Power $(\mathrm{kW})$ & Natural circulation flow rate $(\mathrm{kg} / \mathrm{h})$ & Power $(\mathrm{kW})$ \\
\hline 1 & 3.53 & 151.0 & 76.1 & 153.2 & 74.7 \\
\hline 2 & 4.51 & 160.2 & 80.8 & 161.6 & 80.2 \\
\hline 3 & 6.82 & 170.3 & 88.0 & 163.0 & 86.2 \\
\hline 4 & 7.80 & 188.3 & 93.6 & 176.7 & 89.5 \\
\hline
\end{tabular}

The height between air cooler and SG is $14.5 \mathrm{~m}$, the height of chimney is 12.8 , the water in SG is $5.1 \mathrm{~m}$, the hydraulic resistance is 105 , and the temperature at the inlet is $33^{\circ} \mathrm{C}$.

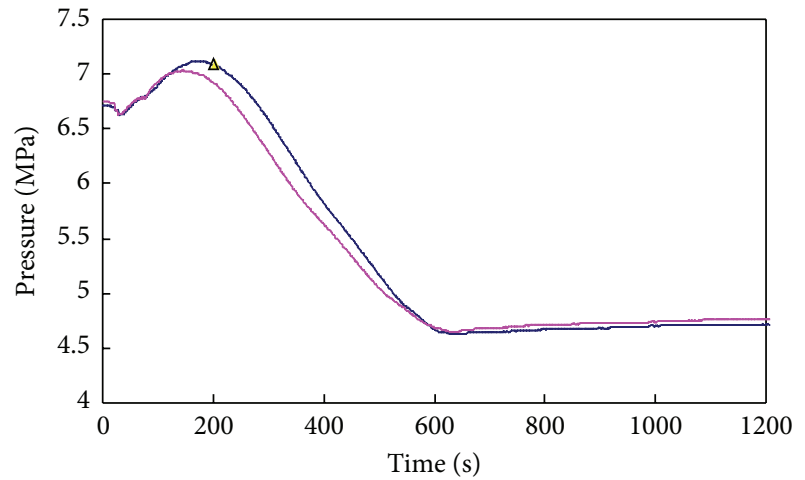

— Apr071101 warm startup mode $\checkmark$ Apr071901 cold startup mode

FIGURE 3: The pressure of cold and warm startup mode.

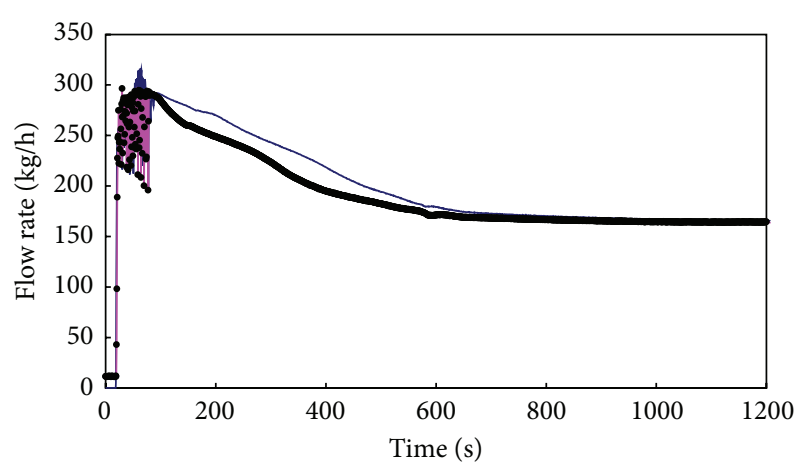

- Apr071901 cold startup mode

- Apr071101 warm startup mode

FIGURE 4: The natural circulation flow rate.

before the startup of transient test, this type of startup mode is defined as warm startup. On the other hand, if the initial condition is cold, or there is no flow in both steam-water circulation loop and air natural circulation loop, this type of startup mode is defined as cold startup.

The typical results of cold and warm startup tests with emergency feedwater are shown in Figures 3-6. The pressure increases before the air natural circulation is established when the residual heat is larger than that absorbed by cold water in air cooler and EFWT. But the pressure begins to drop not only because of the residual heat decay but also

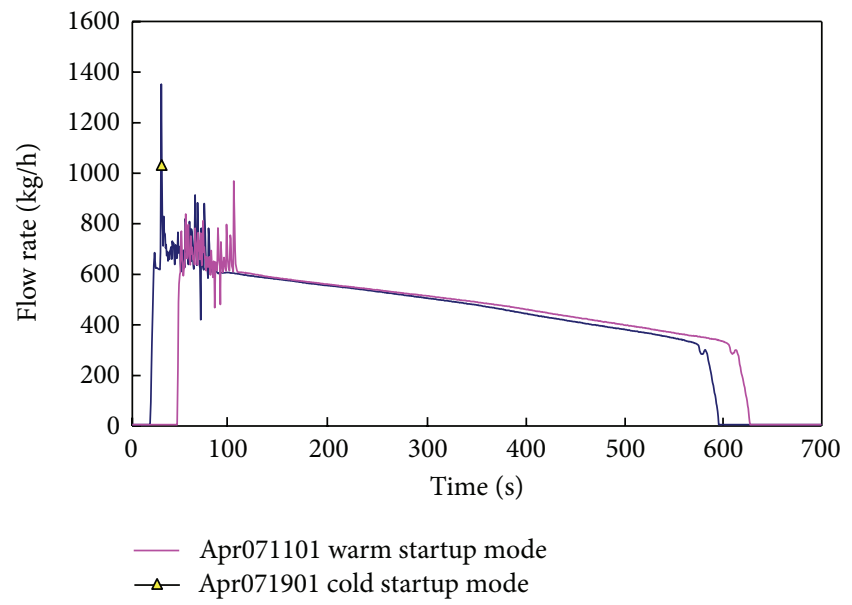

Figure 5: The feedwater flow rate.

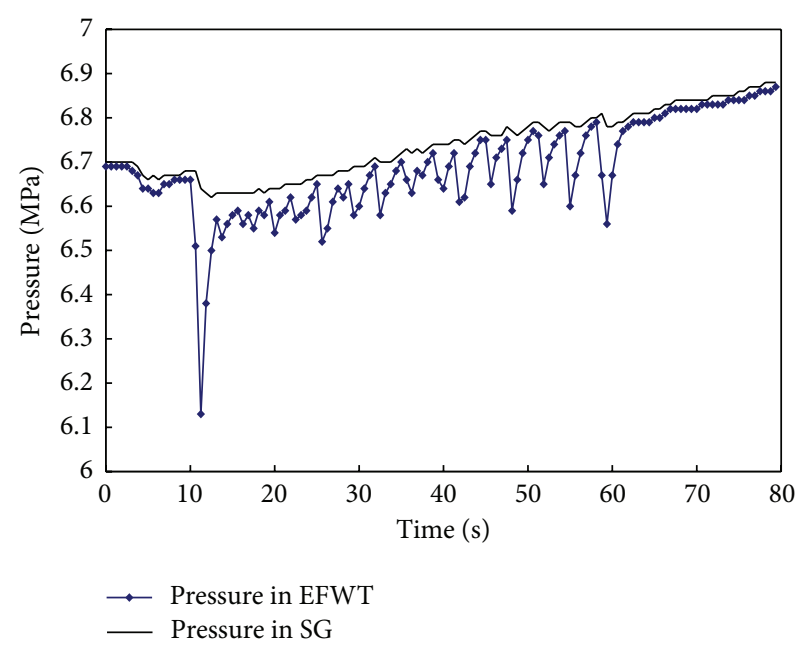

FIGURE 6: The pressure fluctuation when water hammer occurs.

because the air flow rate reaches its maximum. As shown in Figure 3, there is no remarkable difference between cold and warm startup. Figure 4 shows the natural circulation. As the isolation valve is open, the natural circulation is established between SG and air cooler. The flow rate rises to $300 \mathrm{~kg} / \mathrm{h}$. The flow instability happens at the beginning of natural circulation, which is caused by the water hammer that occurs in emergency feedwater tank. The water hammer also results in flow instability of injection from emergency feedwater tank 


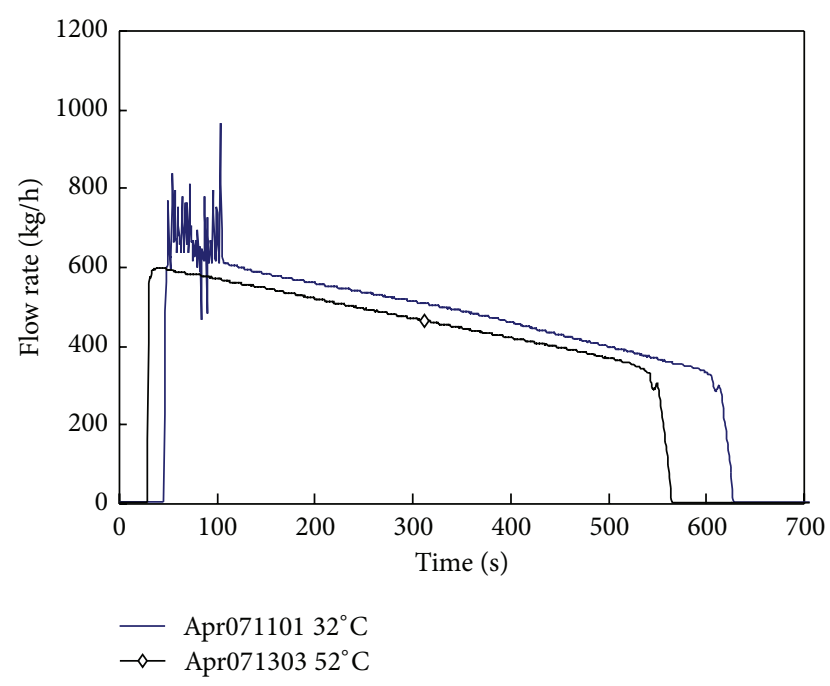

FIGURE 7: Water hammer influenced by feedwater temperature.

as shown in Figure 5. The water hammer occurs in emergency feedwater tank when a great deal of steam, which is rushing into emergency feedwater tank through the pressure balance pipe after the feedwater valve is opened, condenses quickly. The pressure fluctuates in the emergency feedwater tank when the water hammer happens as shown in Figure 6. Some tests have been performed to avoid water hammer's appearance.

4.2.1. Effect of Temperature of Feedwater. The effect of temperature of feedwater in the passive residual heat removal system has been identified at the initial temperatures of $32^{\circ} \mathrm{C}$ and $52^{\circ} \mathrm{C}$ and the other parameters are kept at a constant value. The results are shown in Figure 7. When the temperature of feedwater in the emergency feedwater tank is $52^{\circ} \mathrm{C}$, the water hammer does not happen because the direct contact condensation is related to the temperature of fluid.

4.2.2. Effect of Resistance of Feedwater Loop. In this group of case studies, the resistance of feedwater loop is changed by $+50 \%$ of the reference case, and the other parameters are the same. The results are shown in Figure 8. As the resistance of feedwater loop increases, the feedwater flow rate and steam flow rate decrease accordingly. As a result there is not flow instability.

\section{Code Development and Verification}

MISAP2. 0 code is a typical code that is used to analyze steady and transient performance of the secondary passive residual heat removal system.

5.1. Mathematical Model. A basic assumption is that onedimensional approach is used.

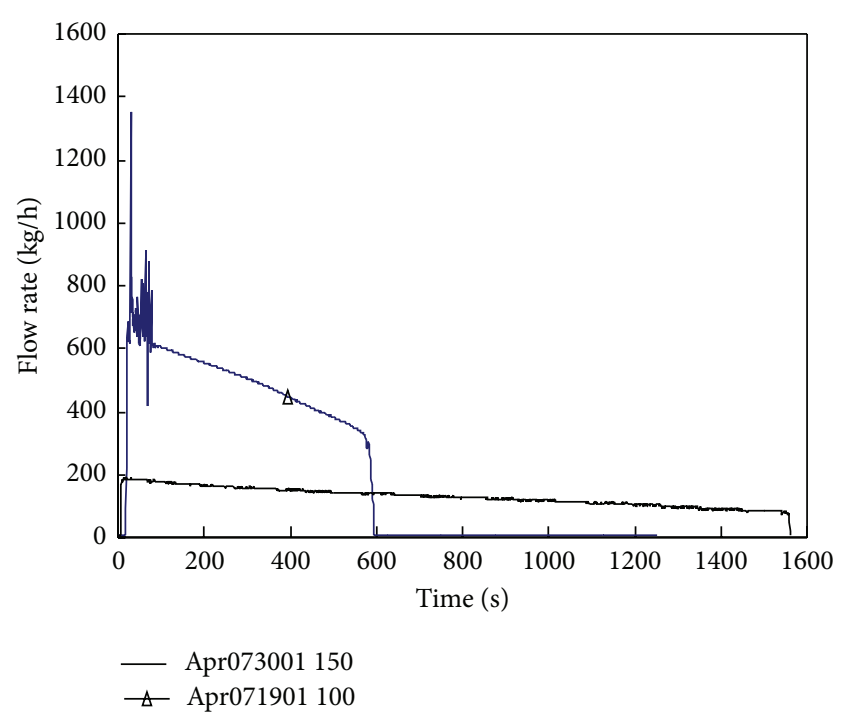

FIGURE 8: Water hammer influenced by resistance of feedwater loop.

5.1.1. Single-Phase Conservative Equations. Equation of continuity is

$$
\frac{\partial \rho}{\partial \tau}+\frac{1}{A} \frac{d W}{d Z}=0
$$

where $W$ is flow rate and $\rho$ is density.

Equation of momentum is

$$
\frac{\partial W}{\partial \tau}=-A \frac{\partial P}{\partial Z}-\frac{\partial}{\partial Z}\left(\frac{W^{2}}{\rho A}\right)-\rho g A-U_{h} f \frac{W^{2}}{2 \rho A^{2}},
$$

where $A$ is the cross-sectional area of the flow channel; $P$ is pressure; $U_{h}$ is wetted perimeter; $f$ is friction coefficient; $g$ is the gravitational acceleration.

Equation of energy is

$$
\begin{array}{r}
\frac{\partial}{\partial \tau}\left[\rho\left(u+\frac{V^{2}}{2}\right)\right]+\frac{\partial}{\partial Z}\left[\rho\left(u+\frac{V^{2}}{2}\right) V\right] \\
=\frac{q U_{k}}{A}+\frac{1}{A} \int_{A} q_{V} d A-\frac{\partial}{\partial Z}(V P)-\rho g V,
\end{array}
$$

where $h$ is enthalpy; $V$ is velocity; $q_{V}$ is heat generation rate of the fluid; $U_{k}$ is heated perimeter. The gravitational work and the work related to the kinetic energy variation can be neglected and the heat generation of the fluid is ignored; the equation can be simplified as follows:

$$
\rho \frac{\partial h}{\partial \tau}+\frac{W}{A} \frac{\partial h}{\partial Z}=\frac{q U_{h}}{A}+\frac{\partial P}{\partial t} .
$$

5.1.2. Two-Phase Mixture Conservative Equations. Equation of continuity is

$$
\frac{\partial}{\partial t}\left[\alpha \rho_{g}+(1-\alpha) \rho_{f}\right]+\frac{1}{A} \frac{\partial W}{\partial Z}=0,
$$




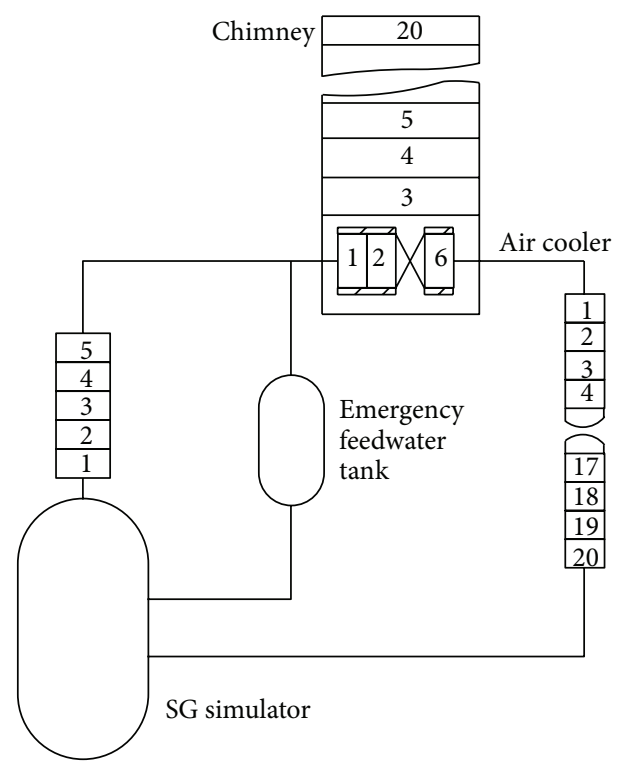

FIGURE 9: MASAP nodalization diagram of the test facility.

where $\alpha$ is void fraction; subscripts $g$ and $f$ stand for steam and saturated liquid, respectively.

Equation of momentum is

$$
\frac{\partial}{\partial \tau}(\rho V)+\frac{\partial}{\partial Z}\left(\rho V^{2}\right)=-\frac{\partial P}{\partial Z}-\frac{1}{A} \int_{U} \tau_{f} d U-\rho g .
$$

Equation of energy is

$$
\frac{\partial}{\partial t}\left[(1-\alpha) \rho_{f} h_{f}+\alpha \rho_{g} h_{g}\right]+\frac{1}{A} \frac{\partial}{\partial Z}[W h]=\frac{q U_{h}}{A}+\frac{\partial P}{\partial t} .
$$

\subsubsection{Emergency Feedwater Tank. Consider}

$$
W_{\text {tank }}=\sqrt{\frac{2 g \Delta H}{\xi}} \rho A_{\text {tank }} .
$$

\subsubsection{Air Loop. Momentum equation is}

$$
\begin{aligned}
\frac{\partial W_{a}}{\partial \tau} \int_{0}^{L y} \frac{1}{A} d z= & -\int_{0}^{L y} \frac{\partial P}{\partial Z} d z-\int_{0}^{L y} \frac{1}{A} \cdot \frac{\partial}{\partial z}\left(\frac{W_{a}^{2}}{\rho A}\right) d z \\
& -\int_{0}^{L y} \rho g d z-W_{a}^{2} \int_{0}^{L y} \frac{U_{h}}{A} f \frac{1}{2 \rho A^{2}} d z,
\end{aligned}
$$

where $L y$ is the chimney height.

5.2. Numerical Model. In view of the fact that two loops closely couple with each other due to energy and momentum interactions, the two loops are solved together. Figures 9 and 10 show MASIP2. 0 nodalization diagram of test facility and SG. After the discretization of the spatial derivative terms in

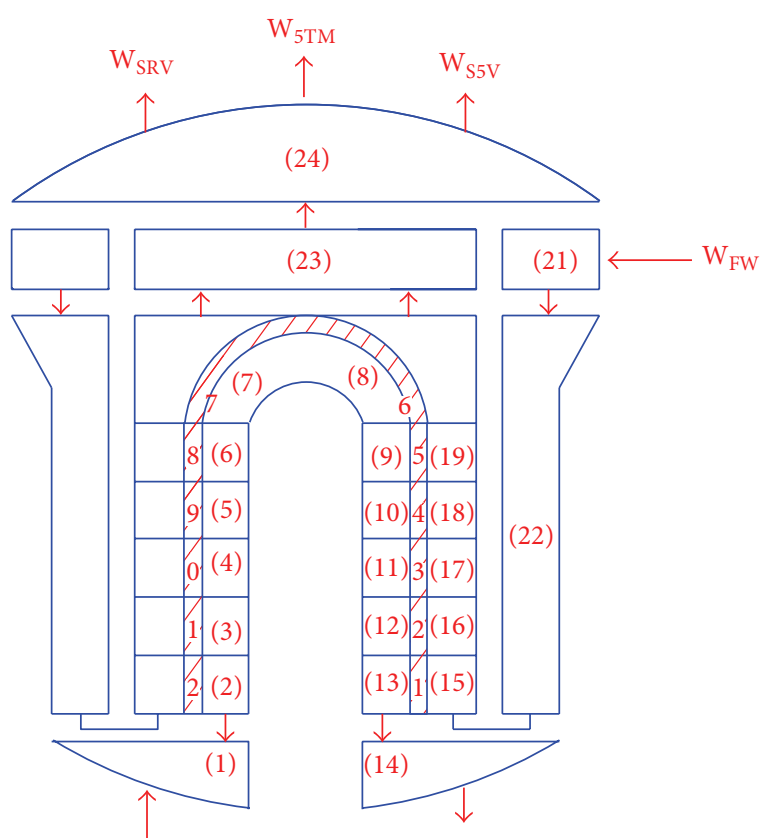

FIGURE 10: MASAP nodalization diagram of SG.

the equations, the following ordinary differential equations are obtained:

$$
\begin{gathered}
\frac{d \vec{y}}{d t}=\vec{f}\left(t, \vec{y}, \vec{y}^{\prime}\right), \\
\vec{y}\left(t_{0}\right)=\vec{y}_{0} .
\end{gathered}
$$

Therefore, the whole system dynamic simulation can be solved as an initial value problem. For the stiff system of differential equations, Gear's algorithm is used traditionally.

5.3. Steady State Calculation. During the steady state calculation, several parameters, such as natural circulation flow rate, flow rate of air, temperature of condensate, and air at outlet of chimney, are calculated. And the calculations of MASIP2.0 are compared with the experimental data shown in Table 4. It shows that the error between calculation and experimental data is less than $10 \%$.

5.4. Transient State Calculation. The transient calculation results of cold startup model test are compared with experimental data in Figures 11 and 12. Figure 11 shows the pressure comparison between calculation and test. The pressure increases before the air natural circulation is established when the residual heat is larger than that absorbed by cold water in air cooler and EFWT. MISAP2.0 code predicts the pressure well. However, the quantitative description is poor in the initial period of the transient. The reason is that there is no direct contact condensation model in the code. Then, the calculated flow rate of feedwater is less than experimental data, as shown in Figure 12. As a result the calculation of pressure is higher than that in the tests. As for the absence of direct contact condensation model, the water hammer is not observed. 
TABLE 4: Comparison between the calculation of MISAP2.0 and experimental data.

\begin{tabular}{|c|c|c|c|c|c|c|c|c|}
\hline \multirow[b]{2}{*}{ Number } & \multicolumn{4}{|c|}{ Test } & \multicolumn{4}{|c|}{ Calculation of MISAP2.0 } \\
\hline & $\begin{array}{c}\text { Natural } \\
\text { circulation flow } \\
\text { rate }(\mathrm{kg} / \mathrm{h})\end{array}$ & $\begin{array}{c}\text { Temp. of } \\
\text { condensate } \\
\left({ }^{\circ} \mathrm{C}\right)\end{array}$ & $\begin{array}{l}\text { Flow rate of } \\
\text { air }(\mathrm{kg} / \mathrm{s})\end{array}$ & $\begin{array}{c}\text { Temp. of air at } \\
\text { outlet }\left({ }^{\circ} \mathrm{C}\right)\end{array}$ & $\begin{array}{c}\text { Natural } \\
\text { circulation flow } \\
\text { rate }(\mathrm{kg} / \mathrm{h})\end{array}$ & $\begin{array}{c}\text { Temp. of } \\
\text { condensate } \\
\left({ }^{\circ} \mathrm{C}\right)\end{array}$ & $\begin{array}{c}\text { Flow rate of } \\
\text { air }(\mathrm{kg} / \mathrm{s})\end{array}$ & $\begin{array}{l}\text { Temp. of air } \\
\text { at outlet }\left({ }^{\circ} \mathrm{C}\right)\end{array}$ \\
\hline 1 & 184.0 & 218.5 & 0.581 & 184.3 & 194.6 & 218.3 & 0.600 & 184.1 \\
\hline 2 & 165.8 & 194.9 & 0.582 & 185.5 & 183.4 & 216.9 & 0.595 & 177.6 \\
\hline 3 & 198.8 & 255.2 & 0.579 & 181.2 & 219.9 & 249.6 & 0.609 & 202.1 \\
\hline 4 & 164.6 & 229.3 & 0.515 & 193.0 & 180.6 & 246.3 & 0.550 & 188.6 \\
\hline
\end{tabular}

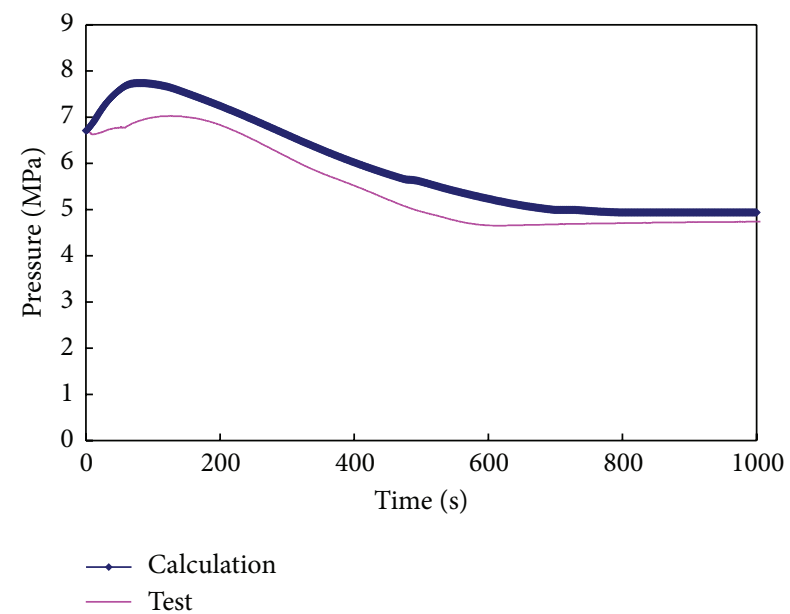

FIGURE 11: The pressure comparison between calculation and test.

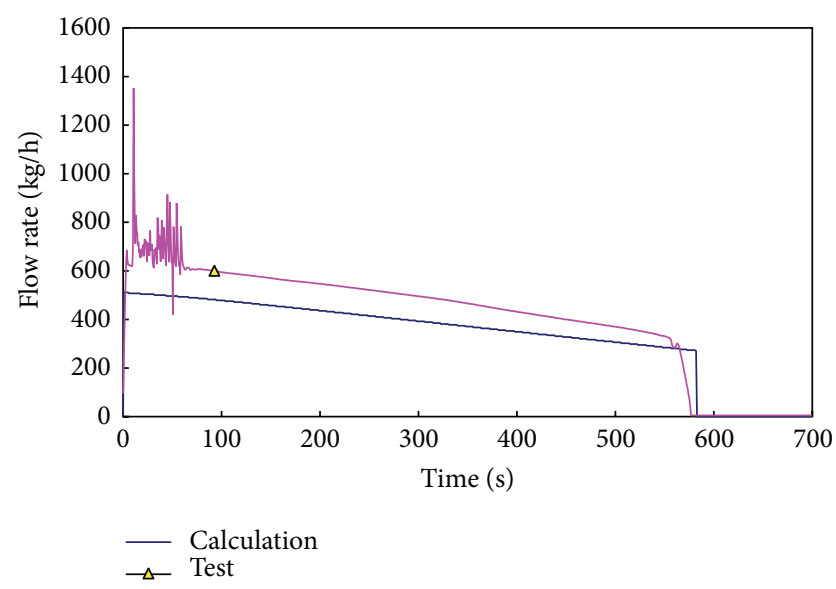

FIGURE 12: The flow rate comparison between calculation and test.

\section{Conclusion}

The passive residual heat removal system (PRHRS) characteristics of Chinese advance pressurized water reactor (CAPWR) have been experimentally investigated. Based on the investigations, the following conclusions are drawn.

(1) A total of 280 sets of tests at steady state have been implemented to investigate the effect of some parameters on the passive residual heat removal system.
The result shows that the height of chimney has great influence on natural circulation flow rate. And the effect of the initial pressure and hydraulic resistance is small or negligible.

(2) Based on the experiments, semiempirical model for analyzing passive residual heat removal system is established, and the calculation shows good agreement with experimental data. It can be applied to system arrangement design for PRHRS of Chinese advanced PWR.

(3) In case of station blackout accident, the transient characteristics of passive residual heat removal system were studied. The natural circulation and injection of feedwater are very useful for removal of decay heat.

(4) The increase of feedwater's initial temperature and resistance of feedwater loop is useful to avoid the water hammer.

(5) A code MISAP2.0 has been developed, and the transient tests are used to verify the prediction of MISAP2.0. The calculated parameter variation trend is reasonable. However, the flow fluctuation and water hammer cannot be simulated by MISAP2.0. Now the direct contact condensation is under development for next version of MISAP.

\section{Nomenclature}

A: Flow area $\left(\mathrm{m}^{2}\right)$

$f$ : Friction factor

$g$ : Gravity acceleration $\left(\mathrm{m} / \mathrm{s}^{2}\right)$

$h$ : Specific enthalpy $(\mathrm{J} / \mathrm{kg})$

$K$ : Loss coefficient

$H$ : Emergency feedwater tank water lever (m)

$P$ : Pressure $(\mathrm{Pa})$

$q$ : Heat flux $\left(\mathrm{W} / \mathrm{m}^{2}\right)$

$t$ : Time (s)

$U:$ Heated perimeter $(\mathrm{m})$

$U_{e}:$ Wetted perimeter $(\mathrm{m})$

$W$ : Mass flow rate $(\mathrm{kg} / \mathrm{s})$

$z$ : Special coordinate $(\mathrm{m})$

$\alpha$ : Void fraction

$\rho:$ Density $\left(\mathrm{kg} / \mathrm{m}^{3}\right)$. 


\section{Conflict of Interests}

The authors declare that there is no conflict of interests regarding the publication of this paper.

\section{References}

[1] "Passive safety systems and natural circulation in water cooled nuclear power plants," IAEA-TECDOC-1624, IAEA, Vienna, Austria, 2009.

[2] "Status of advanced light water reactor designs 2004," IAEATECDOC-1391, IAEA, Vienna, Austria, 2004.

[3] S. Kim, B. Byoung-Uhn, C. Yun-Je, P. Yu-Sun, K. Kyoung-Ho, and Y. Byong-Jo, "An experimental study on the validation of cooling capability for the passive auxiliary feedwater system (PAFS) condensation heat exchanger," Nuclear Engineering and Design, vol. 260, pp. 54-63, 2013. 


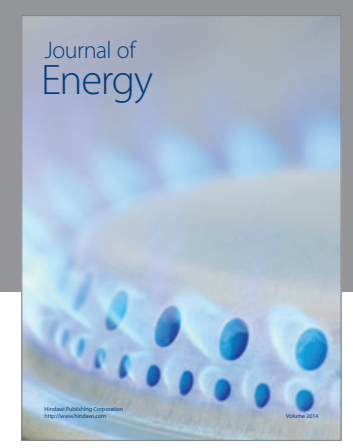

Journal of

Industrial Engineering
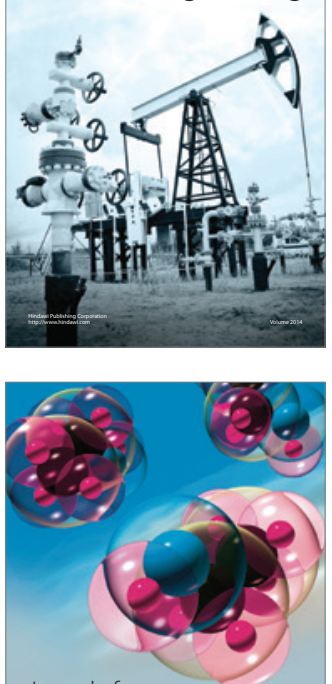

Fuels
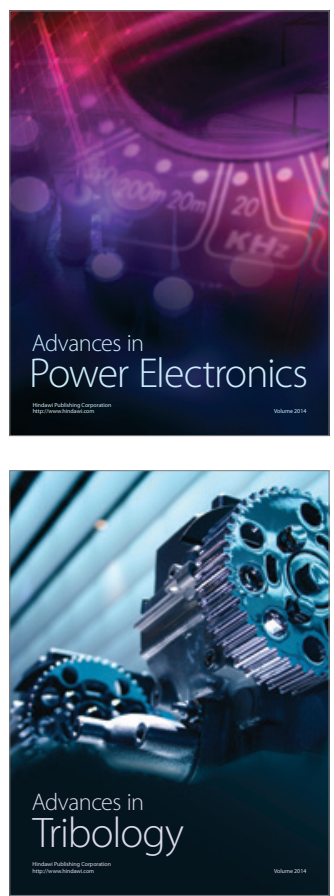

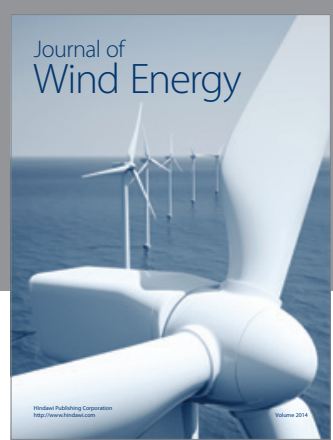

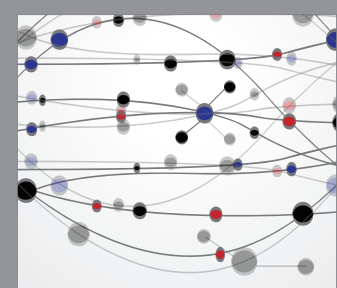

The Scientific World Journal

Submit your manuscripts at http://www.hindawi.com

Journal of

Structures
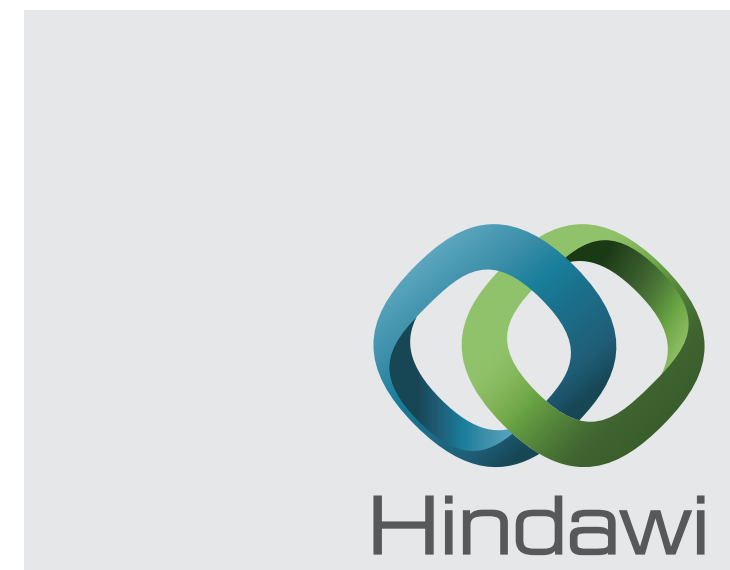

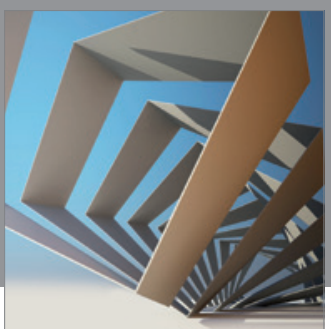

Rotating

Machinery
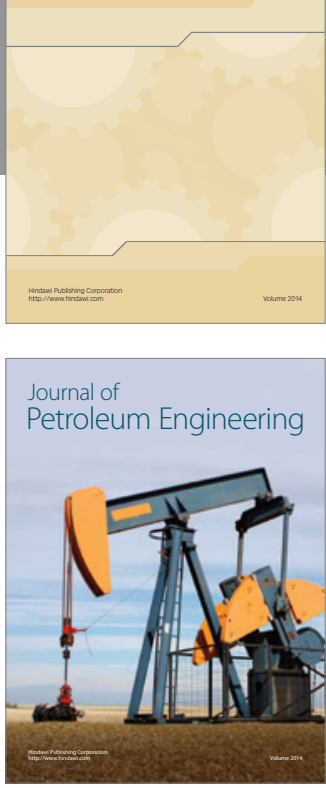

Journal of

Solar Energy
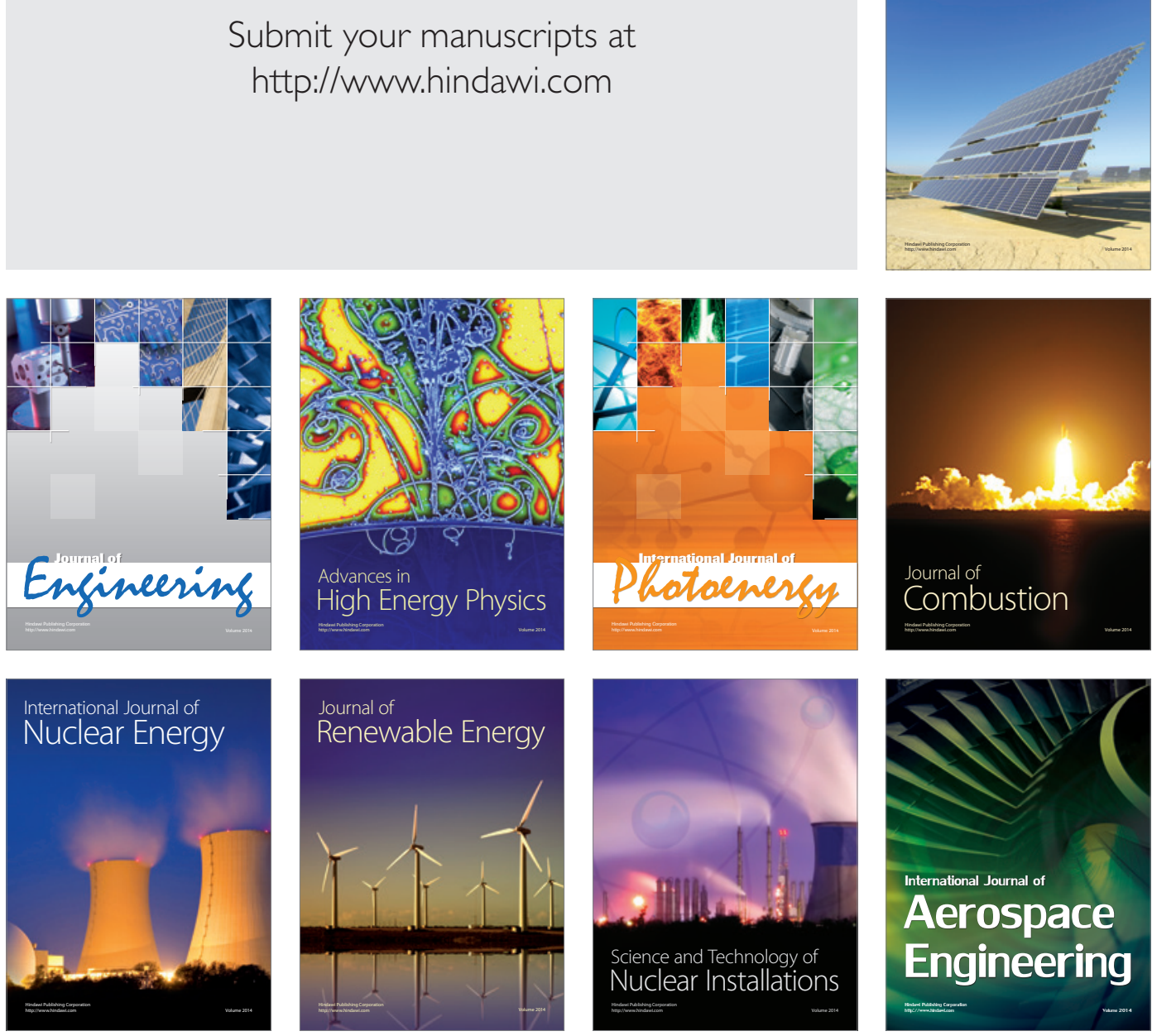